\title{
Neuropsychopharmacology: Are We Ready for a Paradigm Shift?
}

Roger E. Meyer, M.D.

The "paradigm shift" in the title of this article refers to molecular biology. The real challenge to molecular biologists interested in applying their methods to an understanding of psychiatric disorders involves the development of models that account for gene/environment/development interaction. Because of the existence of homologous animal models of addictive disorders, as well as a rich body of clinical observations and clinical and behavioral research, and recent data suggesting that chronic exposure to addictive drugs results in changes in gene expression in neurons from behaviorally relevant brain regions, addictive disorders offer a serendipitous model (to molecular biologists) that may have relevance to subsequent application in other areas of psychiatry and psychology. [Neuropsychopharmacology 14:169-179, 1996]
KEY WORDS: Addictive disorders; Alcoholism; Molecular and cellular biology; Animal models; Craving; Dopamine; Nucleus accumbens

In December 1964, 18 months before the end of my psychiatric residency, I attended my first American College of Neuropsychopharmacology (ACNP) meeting as the guest of Dr. Alberto DiMascio. The meeting had a profound and lasting impression on me. Psychopharmacology offered not only the promise of improved patient outcome, it also offered the promises of new understanding of the pathophysiology of major mental disorders. There is no question that psychopharmacology launched a revolution in the clinical care of patients and in the development of new methods for the evaluation of treatment. After more than 30 years, the question still remains whether it has begun to fulfill its promise to

From the George Washington University Medical Center, Washington, DC.

An earlier version of this paper was delivered at the Annual Meeting of the American College of Neuropsychopharmacology by Roger E. Meyer, Past President, in San Juan, Puerto Rico, December 14,1994 , as his Plenary Address.

Address correspondence to: Roger E. Meyer, M.D., Vice President for Medical Affairs/Executive Dean, George Washington University Medical Center, 2300 Eye Street, N.W., Suite 713, Washington, DC 20037.

Received December 30, 1994; revised March 29, 1995; accepted April 26, 1995 increase our understanding of the etiology of major mental illness. Has psychopharmacology represented a scientific revolution, or has it simply served as an effective challenge to the predominant psychoanalytic paradigms that still held sway into the 1970s: Because dynamic psychiatry saw psychopathology as "functional" for patients, its paradigm could not easily incorporate psychopharmacology and other somatic treatments aimed at treating "dysfunctional" cognition, emotion, and behavior. Psychopharmacology undermined the validity and usefulness of psychodynamic explanations of the etiology of mental disorders, but it has not yet resulted in a new paradigm to explain those disorders.

In his classic text, The Structure of Scientific Revolutions, Kuhn (1970) highlighted the scientific developments in the "hard sciences" associated with the names of Copernicus, Newton, Lavoisier, and Einstein. Each was associated with the rejection of an earlier theory, in favor of one that was not compatible with it. Each produced a shift in the problems available for scientific scrutiny-and the requirements of evidence. Kuhn developed the concept of "paradigms" and "paradigm shifts" (scientific revolutions). "Real science" is based on "shared paradigms" that bring together the same standards and rules of scientific practice. "In the absence of a paradigm or some candidate for a paradigm, all of the facts that could possibly pertain to the development of 
a given science are likely to seem equally relevant." Moreover, "in the absence of a reason for seeking some particular form of information, . . . fact gathering is restricted to the wealth of data at hand" (Kuhn 1970, p. 15).

This audience should have no difficulty recognizing the paradigm shift that occurred in the 17th century. Prior to that time, the Aristotelian model opined that "an object falls because its 'nature' drives it toward the center of the universe" (Kuhn 1970, p 104). When clinical psychopharmacology challenged this type of tautological reasoning in academic psychiatry, the field returned to the traditions of descriptive psychiatry with the notion that greater diagnostic specificity would lead to a more rational pharmacotherapy - and a greater likelihood of linking psychopharmacology to an increased understanding of pathophysiology. Although the "jury" must still be considered to be "out" regarding the validity of this assumption, the efficacy of some antidepressants in the treatment of mood disorder, panic disorder, obsessive-compulsive disorder, and some eating disorders would appear to argue against a strong case for drug/disorder specificity (based on current nosology and criteria) as the "royal road" to understanding pathophysiology. Indeed, Kuhn would probably recognize this period in our field's history as being notable for the absence of a paradigm - an observation that seems to be reinforced by the many diagnostic categories and heterogeneous criteria within the three successive volumes of diagnostic and statistical manuals of the American Psychiatric Association over the past 15 years. Using analogies from the "hard sciences," he would regard this period, although scholarly, as pre-scientific. "To reject one paradigm without simultaneously substituting another is to reject science itself" (Kuhn 1970, p 79). The discovery of digitalis improved the treatment of some patients with edema, but the descriptive literature on the varieties of dropsy continued.

Developments in psychopharmacology have led to a variety of new theories of mental disorder, which have seemed consistent with the purported mechanisms of action of psychoactive drugs. When Heinz Lehmann commented about "life's depletions" at an ACNP meeting in the 1970s, there was an understandable metaphoric linkage between a theoretical deficiency of norepinephrine in the synapse, the acute effects of known antidepressants, and the depleted persona of melancholia. But with the introduction of each new drug class of antidepressant and the recognition that acute drug effects did not account for the temporal realities of recovery through medication, one theory replaced another. Even with our growing knowledge base of receptor subtypes and second messenger function, we have come to a point where there is no obvious pathophysiologic paradigm of any psychiatric disorder that can be easily derived from our growing pharmacopeia. New para- digms must account for observations that cannot be explained with existing models but new paradigms are also the source of new methods, new problem fields, and new standards of acceptable solutions. "The reception of a new paradigm often necessitates a redefinition of the corresponding science" (Kuhn 1970, p 103).

During my 30 years of participation in the meetings of the ACNP, we have been offered a marvelous interdisciplinary forum and multidisciplinary membership through the era that focused on neurotransmitter-based models of pathophysiology. But the self-study activity that we began last year revealed a discomfort among some of our members with the growing influence of molecular neurobiology (and molecular neurobiologists) within the ACNP. This angst was also reflected in the efforts by some of our members to establish the American Society of Clinical Psychopharmacology and to challenge the Program Committee, the Credentials Committee, and the leadership of our society regarding the continuing relevance of our organization to clinical psychopharmacology. There seemed to be real concern about the amount of molecular biology on the program and the numbers of molecular biologists approved for membership in the ACNP.

Molecular biology has presented a challenge to our membership, much as it has confronted the corpus of pharmacology as a discipline. As we know, some medical schools have even dropped pharmacology as a distinct department and the old departmental boundaries across the basic sciences of biochemistry, physiology, and pharmacology have fallen in the face of the emerging paradigm shift offered by molecular biology. Will neuropsychopharmacology be submerged in the new molecular neurobiology? What can molecular neurobiology mean to us as a discipline? Is there no way to reconcile the explicit reductionism of the emerging paradigm with the multivariate complexity of our data? Are we ready for the revolution that is affecting the rest of medicine? Will molecular biology offer us the unifying paradigm that our field has lacked since the introduction of the first antidepressants, anxiolytics, and neuroleptics challenged the usefulness of psychoanalysis as an explanatory model of psychopathology and its treatment?

During the past 15 years, each report of genetic linkage of major mental illness has been followed by a failure to replicate. The highs and lows that have greeted these reports in our literature have raised doubts among geneticists about the readiness of our syndromal models for 21st century biology. Our genetic models have presumed a deterministic connection between a faulty gene and the syndromes defined by the DSM's since 1980, whereas we have too often ignored the rich literature on developmental and environmental risk factors that antedate DSM-III. Even a well-defined genetic abnormality like phenylketonuria will not result in a specific disorder unless phenylalanine is in the diet. In 
order for our field to connect to the new paradigms offered by molecular biology, clinical investigators, geneticists, and molecular biologists will have to be ready to explore the interaction of genetic, environmental, and developmental factors. Is there any part of our field that may be more ready for the insights of molecular biology? I submit that addictive disorders are ripe for the paradigm shift!

\section{ADDICTIVE DISORDERS: READY FOR THE PARADIGM SHIFT}

Table 1 describes the eight reasons why I believe that addictive disorders are ready for the paradigm shift. The text that follows represents an elaboration of that rationale. Table 2 describes seven aspects of addictive disorders that will, likely, not be affected by the paradigm shift. In fact, molecular biologists may be able to help us define the pathophysiology of the negative mood states associated with chronic intoxications, acute withdrawal and "protracted abstinence" (Meyer 1989).

\section{The Clinical Dependence Syndromes}

Psychoactive substance dependence disorders, like many other categories within DSM-IV, are defined by a cluster of behavioral symptoms that conform more to our concept of a syndrome than a clearly delineated disease state or category. The core dependence syndrome, across all classes of drugs of abuse, is defined on the basis of drug seeking behavior that continues despite adverse consequences and includes a persistent risk of relapse after withdrawal. Of all of the diagnostic categories within DSM-IV, animal models come closest to specific human disorders in the drug seeking behavior that has been identified as the core element of the dependence syndromes. On the other hand, the criteria are descriptive and atheoretical. Whereas the animal models offer rich possibilities for molecular neurobiologists, the diagnostic criteria do not approach the richness of earlier and some current clinical research literature that led to testable theories regarding the causes of relapse. This literature needs to be rediscovered by molecular neurobiologists, as well as by clinical investigators.

\section{Homologous Animal Models of Addictive Disorders}

In the years after the development of animal models of drug self-administration, behavioral pharmacologists defined the dimensions of the stimulus control of drug seeking and self-administration behavior-and its modification by drugs affecting synaptic function (Weeks 1963; Yanagita et al. 1969; Woods and Schuster 1968; Koob and Bloom 1988; Koob 1992). Alcohol researchers described the contribution of pharmacogenetics in the differential sensitivity of strains of mice and rats to the effects of ethanol and in alcohol preference drinking paradigms. Alcohol consumption in animal models can also be affected significantly by schedules of reinforcement and/or by association with other reinforcers. Within the most relevant of these paradigms, alcohol self-administration is associated with its pharmacologic effects, and not its nutritional value (summarized by Meyer and Dolinsky 1991).

\section{Mechanisms of Drug/Alcohol Reinforcement}

Wise and Bozarth (1987) have characterized the drug self-administration behavior of monkeys and rats as "homologous" models of human drug dependence. They proposed the psychomotor stimulant theory of reinforcement, which linked the reinforcing properties of

Table 1. Addictive Disorders: Ready for the Paradigm Shift?

1. Reasonably well-defined concepts that can be described at clinical, animal model, cellular, and molecular levels (e.g., tolerance, acute withdrawal reactions, drug/alcohol self-administration behavior, post-withdrawal signs and symptoms).

2. Heritable and/or developmental risk factors - as yet unspecified.

3. A clinical research literature which includes DSM-IV - but also other relevant clinical observations (e.g., persistent insomnia in alcoholics, abnormalities of HPA axis function that remain during abstinence).

4. Homologous animal behavioral models of the disorders.

5. An existing and growing knowledge base of brain mechanisms relative to drug-related reinforcement and the neurobiology of anticipatory states.

6. Changes in gene expression consequent to chronic drug/alcohol exposure.

7. Clinically derived theories of mechanisms of relapse and etiology that can be tested with paradigms drawn from molecular neurobiology.

8. Some promising pharmacotherapies for treating opiate and alcohol dependence. 
Table 2. Areas of Addictive Disorders that Will Not Be Affected by Paradigm Shift

1. The role of faith in the recovery process.

2. Spontaneous recovery in the absence of treatment.

3. The role of meaning, quality of relationships, hope, and other factors on the onset, course, and prognosis of the disorder. As Seymour Kety has been quoted, "We will some day have a biochemistry of memory, but not of memories."

4. The role of motivation (compliance) in maintaining involvement in Alcoholics Anonymous, the application of relapse prevention/coping skills strategies by patients (clients), the consumption of medications designed to discourage relapse (e.g., disulfiram in alcoholics, naltrexone in opiate addicts).

5. The continued importance of clinical criteria in defining outcome.

6. The importance of well-controlled clinical outcome study designs to assess new treatment interventions (including pharmacotherapies).

7. The role of comorbid psychopathology on the onset, course, and prognosis of addictive disorders may or may not be affected by the new paradigm. This is partly a function of the complex relationship between addictive disorders and other comorbid psychiatric disorders and/or psychiatric symptoms (e.g., psychiatric disorders as risk factors, modifiers of course and treatment response, psychiatric symptoms as a consequence of chronic intoxications and as a residua during abstinence, and moods as conditional stimuli associated with drug self-administration) (Meyer 1986).

drugs of abuse to their psychomotor stimulant effects. Increased locomotor activity results from drug activation of dopamine neurons of the ventral tegmental area (VTA) and substantia nigra, whereas reinforcement is mediated by drug effects on dopamine neurons in the VTA and the nucleus accumbens (Wise and Bozarth 1987). Dopamine release in the nucleus accumbens consequent to the administration of drugs that are abused by humans has been confirmed using in vivo microdialysis techniques (DiChiara and Imperato 1988). The model is also consistent with the effects of these drugs in brain stimulation reward (BSR) paradigms, where drug administration lowers the threshold of the reinforcing electrical stimulus (Kornetsky and Porrino 1992).

The evidence for a primary role for dopamine neurons in the reinforcing properties of drugs is strongest in the case of cocaine and other stimulants (Ritz et al. 1987; DiChiara and Imperato 1988). Administration of dopamine receptor antagonists results in increased stimulant self-administration (Yokel and Wise 1975). Both $D_{1}$ and $D_{2}$ receptor subtypes have been implicated in cocaine reinforcement (Koob 1992). Cocaine binds to the dopamine transporter and effectively blocks dopamine reuptake (Ritz et al. 1987). Nevertheless, Koob (1992) notes the relative paucity of data regarding efferent mechanisms through which the nucleus accumbens may mediate positive reinforcement and suggests that the connection between the nucleus accumbens and the substantia innominata-ventral palladium may be important. He also suggests a role for the amygdala as a mediator of drug reinforcement/reward.

There is also evidence that opiate reinforcement involves activation of dopamine neurons, but via a different mechanism than reinforcement associated with stimulant administration. Opiates may increase the firing rate of dopamine neurons by activating mu receptors in the VTA and nucleus accumbens producing local disinhibitory effects on dopamine neurons. The effects of opiates on the VTA are blocked by naloxone (Britt and Wise 1983), whereas naloxone does not block the reinforcing effects of cocaine. Opiate reinforcement can also occur independent of the dopamine system. Rats will self-administer opioid peptides in the region of the nucleus accumbens (Goeders, Lane, and Smith 1984), and lesioning of the nucleus accumbens with 6-OHDA produces a decrease in cocaine self-administration with no impact on heroin self-administration (Pettit et al. 1984). Koob has summarized these data to conclude that "the reinforcing actions of opiates may involve both a dopamine-dependent (VTA) and dopamine-independent (nucleus accumbens) mechanism" Koob (1992a).

Finally, several lines of evidence suggest that opioid peptides, serotonin, dopamine, and GABA are all involved in alcohol reinforcement (Koob and Bloom 1988). Acute ethanol administration also inhibits calcium flux through the NMDA receptor-gated ion channel. This could account for some of the acute behavioral effects of ethanol. Reed and Hunter (1984) found that morphine increased alcohol self-administration in rats, whereas narcotic antagonists decreased ethanol drinking. One immediate implication of this experimental work has been the testing of the narcotic antagonist naltrexone in alcohol-dependent subjects, where it has turned out to be a promising adjunct to behavioral relapse prevention therapy (Volpicelli et al. 1992; O'Malley et al. 1992). Whereas dopamine may play some role in alcohol reinforcement, the picture, as described by Koob and Bloom (1988), suggests that multiple neurotransmitters may be involved in alcohol's effects and alcohol-associated reinforcement.

As Koob (1992a) has recently noted, Wise and Bozarth may have been a bit too optimistic in their assessment 
that the acute reinforcing properties of drugs, as reflected in drug self-administration behavior and dopamine concentrations in the synapse of neurons in the nucleus accumbens, serves as an adequate explanation of drug/ alcohol addiction. During the past 30 years, we have gained substantial understanding of drugs as reinforcers, but there are persistent questions concerning the neuroadaptive changes consequent to chronic drug selfadministration that result in human drug/alcohol dependence, and the persistent risk of relapse after withdrawal.

More recently, there has been substantial interest in intracellular events associated with acute drug reinforcement. In last year's Presidential Plenary session, Nestler (the 1994 Efron awardee) summarized the direct evidence of a role for $G$ proteins and the cAMP pathway in drug reinforcement (Nestler 1994). He also postulated that chronic adaptations in these intracellular mechanisms could account for the pathophysiology of addictive disorders. Changes in gene expression consequent to chronic alcohol or drug exposure could account for the long-term changes in brain function that have been associated with addiction. (See later section entitled "Further Thought on Better Integration of Data from Clinical and Molecular Studies").

\section{Clinically Derived Theories of Etiology of Drug/Alcohol Dependence and Relapse}

Since physicians and behavioral psychologists became involved in the treatment of addictive disorders, there has been considerable speculation on the factors that contribute to relapse after abstinence. Relapse appears to be a problem that is a compound of two elements: a tendency to use again after a period of abstinence, and the rapid reinstatement of the elements of dependence as described in DSM-III-R, DSM-IV, and ICD 10. At least two distinct theories have been invoked to explain relapse and the rapid reinstatement of dependence: conditioning models and homeostatic models. Regrettably, neither of these has been elaborated to any degree in any of the Diagnostic and Statistical Manuals of the American Psychiatric Association. Indeed, this is a serious limitation of the DSMs in clinical investigation in this field, as in the application of molecular neurobiology to studies of substance dependence disorders.

Conditioning models posit that relapse to drug or alcohol use occurs in those environments or circumstances that have been associated with previous use, as a function of Pavlovian conditioning. Homeostatic models postulate that chronic substance use results in some long-term perturbation of CNS and/or endocrine function, such that drug-free, former addicts do not feel "normal" in the absence of their preferred drug or alcohol. To some extent, both models postulate an antecedent subjective state ("craving" or "desire") which serves as a trigger to drug seeking behavior much as hunger serves as a trigger for eating. In the context of more recent literature, I believe that "craving" is a concept that has been used too loosely by basic scientists and clinical investigators, although it was ignored for too long by behavioral pharmacologists and psychologists. The models described in the following sections may offer a more rigorous approach to defining the construct. The models are not mutually exclusive, but may in fact be additive. In the face of protracted withdrawal, the incentive-motivational properties of a stimulus associated with the positive reinforcing effects of a drug may be even greater than under other circumstances. Both models came out of the Addiction Research Center at Lexington, Kentucky.

Conditioning Models of Relapse. The late Abraham Wikler first proposed a conditioning model to explain relapse in heroin addicts in 1948 (Wikler 1948). Because he viewed the development of physical dependence as the defining stage of opiate addiction, Wikler believed that by a process of Pavlovian conditioning the signs and symptoms of withdrawal (the unconditioned stimulus) are paired to environmental stimuli in settings where the addict has previously experienced withdrawal and drug consumption. He postulated that, over time, these stimuli elicit withdrawal symptoms that result in relapse to heroin use, when a drug-free addict returns home after a period of incarceration (Wikler 1965). Wikler tested his model in studies of incarcerated addicts at Lexington (Wikler 1965), and in experiments in animal models of addictive behavior (Wikler and Pescor 1967). In 1977, O'Brien and colleagues confirmed the conditioning of withdrawal symptoms in human subjects (O'Brien et al. 1977). Despite several efforts to link conditioned withdrawal symptoms to risk of relapse, the model remains heuristically of interest, but unproven. Recently, Baldwin and Koob (1993) have begun to explore the impact of conditioned opiate withdrawal on ambient and drug self-administration behavior in the rat, attesting to the continuing vitality of the theory to researchers.

In addition to evidence of conditioning of the signs and symptoms of withdrawal and of opponent process conditioning as an explanation of "learned tolerance" (Siegel, Hinson, and Krank 1987), there has also long been evidence of the conditioning of drug effects. As noted by Stewart, De Wit and Eikelboom (1984), the question is not whether each of these conditional phenomena occur, the question is which one(s) are relevant to relapse. Pavlov (1926) noted conditioning of morphine's effects in the dog in 1926. Meyer and Mirin (1979) demonstrated evidence of conditioned heroinlike effects in drug-free addicts who continued to selfadminister heroin (despite narcotic blockade with naltrexone) as long as they experienced these conditioned 
effects. Subjects who did not experience conditioned heroinlike effects while on naltrexone, discontinued heroin self-administration after a few doses of heroin. Subjects who received placebo naltrexone in this doubleblind study continued to self-administer heroin across the 10 days of heroin availability. "Craving" for heroin was highest among subjects who anticipated and experienced either the conditioned or unconditioned effects of heroin (a priming effect). Priming effects have also been observed in alcoholics (Hodgson, Rankin, and Stockwell 1979; Kaplan, Meyer, and Stroebel 1983), and conditioned druglike effects have been observed in cocaine-dependent patients (O'Brien et al. 1992) and in animal models (Davis and Smith 1974).

In 1984, Stewart, DeWit, and Eikelboom (1984) summarized the literature on Pavlovian conditioning and addictive behavior. They argued that the literature offered evidence of Pavlovian conditioning of withdrawal reactions, opponent process, and druglike effects; but, they felt that although each of these conditioned responses occurred, each was not an equally compelling explanation of relapse behavior. Would addicts be motivated to return to settings in which they had experienced the discomfort of conditioned (or unconditioned) withdrawal reactions? Moreover, although opponent process conditioning is a parsimonious explanation for the "learned" aspects of tolerance, they postulated that it is the conditioned druglike effects that are responsible for "craving" and "relapse." From a clinical perspective, their model is compatible with the observed tendency of alcoholics and addicts to return to high-risk settings where they have previously been intoxicated. This is generally a major step on the road to relapse. Although clinicians have attributed this tendency to errors of judgment, it is also possible that it is analogous to conditioned place preference models in which rats come to prefer locations in a maze in which they have previously received drug injections (Brown et al. 1991). Conditioned reinforcement could explain the tendency of alcoholics and addicts to return to these high-risk settings.

The model proposed by Stewart, De Wit, and Eikelboom (1984) is also consistent with the priming effects of low loses of a preferred drug on "craving" and drug seeking and consuming behavior, as well as recent data on sensitization that suggest an additive effect when repeated drug use occurs, over time, in the same environment (Stewart and Vezina 1988; Post et al. 1992). Two recent reports using different methods to assess dopamine release in the nucleus accumbens, report dopamine release in association with anticipated voluntary alcohol consumption in the rat (Vavrousek-Jakuba, Cohen, and Shoemaker 1990; Weiss et al. 1992). O'Brien et al. (1992) reported dopamine release in nucleus accumbens after saline injections in rats previously exposed to multiple cocaine injections. In short, a variety of recent studies support a role for the mesolimbic dopamine system in conditioned drug effects, ${ }^{1}$ the conditioned components of behavioral sensitization, and the possible neurobiology of anticipatory states prior to alcohol consumption in alcohol experienced animals. Because this system is also involved in the unconditioned neurotransmitter response associated with drug/alcohol reinforcement, it should be of interest to molecular neurobiologists to explore intracellular neuronal changes that can be triggered directly by drug administration, and by environmental stimuli that have been previously paired to drug administration. Recently, Brown et al. reported that both cocaine administration and exposure to a cocaine-paired environment each produced an increase in locomotion that was accompanied by an increase in Fos expression within specific limbic regions, as well as the basal ganglia (Brown, Robertson, and Fibiger 1992).

In addition to the dopamine system, there is recent evidence that excitatory amino acids may play a role in conditioned effects of stimulant drugs, and in druginduced sensitization (Karler, Calder, and Chauhry 1989). MK 801, a noncompetitive antagonist of the NMDA receptor, blocked both the development of sensitization to stimulants and conditioned amphetaminelike effects. Because learning is an important component to the conditioning of drug effects and sensitization and may be a function of glutamate neurotransmission, it is possible that this excitatory amino acid may play some role in the conditioning process.

Homeostatic Models of Relapse. Relapse to heroin, cocaine, nicotine, and alcohol addiction is most likely to occur in the first 3 to 6 months of abstinence (Meyer 1989). This period may be characterized by physiologic abnormalities, mood dysregulation, and a variety of somatic symptoms-all of which have been theoretically linked to the problem of relapse. A number of investigators have suggested that the signs and symptoms of what Martin and Jasinski (1969) called "protracted abstinence," represent potential targets for a rational pharmacotherapy of addictions (Meyer 1989; Kreek 1992a). Implicit in the construct is the assumption that during this period, addicts don't "feel normal" without their preferred drug. Indeed, Dole and Nyswander (1965) hypothesized that heroin addicts required steady doses of an exogenous opioid to "feel normal," and Kreek and her colleagues have demonstrated that methadone maintained former heroin addicts manifest normal HPA axis function, whereas drug-free former addicts manifest abnormal HPA axis function in a metyrapone challenge test (Kreek 1992a).

\footnotetext{
${ }^{1}$ Data on this topic are not unambiguous (Brown and Fibiger 1992; Finley et al. 1988).
} 
The construct of "protracted abstinence" has been reasonably well described in heroin addicts (earlier) and in alcoholics in Table 3. The concept is a bit more controversial in cocaine-dependent individuals, although Volkow (1991, 1992), Bauer (1992), Herning (1992), and Kreek (1992b) have separately reported persistent differences in cerebral metabolism, motor function, EEG, and HPA axis function in cocaine-dependent individuals after withdrawal. In rats acutely withdrawn from cocaine, Koob (1992b) has reported a substantial elevation in the threshold for brain stimulation reward, suggesting a homologue for withdrawal anhedonia after cocaine withdrawal. Nestler has reported changes in Foslike transcription factors in target neurons consequent to chronic cocaine administration in rats (Nestler 1994). These changes could result in "altered levels of expression of specific target proteins that underlie the adaptive changes in brain function associated with addiction" (Nestler 1994, p 83).

\section{Cellular and Molecular Biology of Addiction: Recent Progress}

With the discovery of opiate receptors and endogenous opioid peptides, it was anticipated that the development of tolerance and/or physical dependence would be reflected in changes in receptor binding or measurable changes in peptide levels. These early expectations have not been borne out by experience. The challenge to investigators attempting to explain tolerance on the basis of changes in neurotransmitter or opioid peptide release has been to differentiate between the observed result as "cause" or "effect" of tolerance. Moreover, investigators must differentiate between "learned tolerance," metabolic tolerance, and pharmacodynamic tolerance. Presumably the latter might be reflected in changes in gene expression that might explain the phenomenon. Residual tolerance persists past the period of acute

Table 3. Protracted Alcohol Abstinence

1. Evidence of heightened risk of relapse in the first 3 to 6 months after withdrawal from alcohol.

2. Persistent anxiety and depressive symptoms, even in the absence of a mood disorder.

3. Persistent abnormalities of sleep architecture and insomnia.

4. Persistent alterations in the gating of auditory-evoked potentials (hyperexcitability) followed by a period of possible latent hyperexcitability.

5. Persistent cognitive impairment (relative to premorbid levels).

6. Neuroendocrine abnormalities, such as nonsuppression in the dexamethasone suppression test. withdrawal and may represent a marker of "protracted abstinence" and "risk of relapse" associated with some addictive disorders.

Bronstein, Prezewlocki, and Akil (1990) reported a decline in mRNA levels of proopiomelanocortin with chronic morphine treatment. According to these investigators, chronic morphine treatment appears to result in preferential production of beta-endorphin 1-27 (which functions as an antagonist at the mu receptor) relative to beta-endorphin 1-31 (which functions as an agonist at this receptor). It is unclear whether there is normalization after withdrawal, or whether the pattern of betaendorphin production associated with chronic morphine treatment persists during a period of "protracted withdrawal." Beitner-Johnson, Guitart, and Nestler (1992) described regionally specific changes in gene expression of a number of second messenger functions in neurons from brain regions associated with the reinforcing effects of opiates. Taken together, these changes should result in decreased dopamine synthesis in nucleus accumbens, and changes in $D_{1}$ receptor function. Chronic morphine treatment results in a decrease in the phosphorylation state of tyrosine hydroxylase in the nucleus accumbens, which decreases the functional activity of this enzyme. Parenthetically, there is upregulation (an increased phosphorylation) of the enzyme in the ventral tegmental area. Chronic morphine treatment also results in a decrease in neurofilament (NF) proteins in dopamine neurons in the ventral tegmental area. These authors speculate that because the NF proteins form a major component of cytoskeleton, it is possible that there are consequent structural alterations in mesolimbic dopamine neurons that reduce the ability of these cells to transmit dopamine signals to postsynaptic cells in the nucleus accumbens. There are also decreased levels of Gi protein with consequent increases in adenylate cyclase and cAMP dependent protein Kinase, altering $\mathrm{D}_{1}$ receptor function. Identical regionally specific changes in dopamine function occur with chronic cocaine administration. These investigators postulate that these changes could result in impairment of the brain's endogenous reward system, with implications for motivation and affect in humans. Do these changes persist to account for some of the persistent psychological signs and symptoms in abstinent former addicts? Are clinical investigators able to identify any commonalities in the postwithdrawal period in opiate and cocaine-dependent subjects that might be explained by the types of cellular and molecular changes in dopamine neurons in rat nucleus accumbens reported by Beitner-Johnson et al. (1992)? It is intriguing that similar molecular and cellular adaptations after chronic ethanol exposure have recently been reported (Fitzgerald and Nestler, in press).

The locus ceruleus is an important mediator of physical dependence to opiates (Nestler 1990). Beitner-Johnson, 
Guitart, and Nestler (1992) also reported that chronic morphine treatment results in upregulation of cyclic AMP at multiple levels in this brain region. Again, it is unclear whether these changes persist beyond the period of chronic opiate administration and acute withdrawal.

There is a good bit of evidence for altered homeostasis following acute withdrawal from chronic high-dose alcohol consumption (Table 3). Clinical investigators need to assess the persistence of abnormal signs and symptoms after alcohol withdrawal and the relationship between these abnormalities and risk of relapse. Recently, Gillin and associates reported a relationship between abnormalities in sleep architecture after alcohol withdrawal and risk of relapse in alcoholic veterans (Gillin et al. 1994). In animal models of alcohol dependence, there is decreased sensitivity to GABAergic agonists and enhanced sensitivity to inverse agonists (Buck and Harris 1990a, 1990b). This change in receptor sensitivity could account for the symptoms of anxiety and the CNS hyperexcitability during alcohol withdrawal. Do these changes persist beyond the period of acute withdrawal? Alterations in sensitivity to ethanol and changes in preferential binding (agonist vs inverse agonist) with chronic alcohol administration may be a consequence of changes in gene expression of BZ-GABA receptor subunits. Chronic alcohol administration results in a $40 \%$ to $50 \%$ reduction in alpha 1 subunit mRNAs in the cerebral cortex of the rat as well as increases in mRNAs of the alpha 6 and beta 2 subunits in cerebellum (Morrow, Montpied, and Paul 1991). Chronic ethanol administration in mice also results in upregulation of the NMDA receptor for at least 8 hours after withdrawal of alcohol (Grant, Valverius, and Hudspith 1990). Withdrawal seizure activity was reduced by the administration of MK 801 (an NMDA receptor antagonist) in this study. Again, as with the BZGABA receptor, it is unclear whether these changes persist beyond the period of acute alcohol withdrawal, and in what ways they are associated with changes in gene expression.

\section{Further Thought on Better Integration of Data from Clinical and Molecular Studies}

Intrinsic to the concept of protracted abstinence is the model of a deficit in homeostasis consequent to chronic drug or alcohol use, which is made manifest when the organism is drug- or alcohol-free. Evidence of residual dysfunction is most apparent in association with acute withdrawal syndromes where homeostasis is restored by drug substitution. At another level, evidence of abnormalities of GABA and NMDA receptor sensitivity are most clear during chronic ethanol administration and during acute withdrawal. At this juncture, the most robust evidence of persistent deficits in homeostasis in alcoholics and opiate addicts comes from clinical studies. Further work is needed to identify persistent residual abnormalities in receptor function and gene expression that may account for the clinical phenomenology. To date, most molecular neurobiologists have not been especially interested in the types of chronic studies that might validate (or fail to validate) the clinically developed construct of "protracted abstinence." If chronic exposure to opiates, cocaine, and alcohol results in changes in gene expression affecting receptor or second messenger function in neurons from behaviorally relevant brain regions, then the clinical reports of patients in treatment that they "feel normal" when on their drug of choice seem more compelling. Molecular neurobiologists might make a major contribution to clinicians if they defined the duration of changes in gene expression and/or receptor function. Are these changes permanent? Do they respond to acute or chronic treatment with receptor antagonists or other drugs that may modify neurotransmitter, receptor, or second messenger function?

\section{A Molecular Biology of Risk?}

Finally, what are the heritable elements and/or antecedent developmental determinants that may contribute to the development of substance dependence? The alcohol literature is replete with reports on the pharmacogenetic determinants of alcohol preference drinking and differential alcohol sensitivity (summarized by Meyer and Dolinsky 1991). Beitner-Johnson, Guitart, and Nestler (1992) have highlighted the comparative ease of inducing conditioned place preference in Lewis (compared to Fisher) rats. Are Lewis rats more vulnerable to the development of "addictive disorders?" In a provocative group of findings, Beitner-Johnson, Guitart, and Nestler (1992) have compared characteristics of mesolimbic dopamine neurons in Fisher and Lewis rats. The differences in the molecular neurobiology of mesolimbic dopamine neurons in drug-naive Lewis rats (compared to Fisher rats) resembled the differences between chronic morphine- and chronic cocaine-treated animals (compared to controls) in outbred Sprague Dawley rats. Like the pharmacogenetic studies of ethanol, these studies suggest that some aspects of vulnerability may be genetically determined. Other investigators have observed that stress serves to amplify the reinforcing properties of stimulants in rats, in a process which appears to involve corticotropin releasing factor and the HPA axis (Cador et al. 1992). Isolation reared monkeys spontaneously drink much greater quantities of ethanol than monkeys reared in a normal environment in proximity to their biologic mothers (Higley et al. 1991). Environmental factors may affect gene expression related to the reinforcing properties of drugs or alcohol and/or the progression from use to dependence. Whereas drug/ alcohol experimentation is a necessary precursor to the 
development of dependence, it is not a sufficient explanation of the phenomenon. Most individuals who experiment with drugs do not go on to a dependent pattern of drug/alcohol use. Although alcohol researchers have long been interested in the problem of differential individual risk (alcohol is a weaker reinforcer than other drugs of abuse), recently researchers in the drug abuse field have become very interested in this issue in animal and human populations. Molecular biology may lead to new paradigms that can account for differential risk based upon the differential initial reinforcing properties of drugs/alcohol, differential vulnerability to conditioning of the reinforcing stimulus properties of drugs/ alcohol and sensitization, as well as differential changes in gene expression of neurons in the mesolimbic dopamine system and the amygdala that could account for the two components of risk of relapse: risk of use after a period of abstinence and the rapid reinstatement of dependence after resumption of use.

\section{CONCLUSION}

No single article can do justice to the extraordinary scientific progress that has been made in the addictions field over the past 30 years. The original point of this text was to ask whether any part of our field of neuropsychopharmacology may be ready for the revolution in molecular biology. During my presidential year, I felt like the rabbi of old who was approached by two men with diametrically opposite views. When I listened to my clinical colleagues who argued against the usefulness of molecular biology to our field and our College, I had to agree that they were correct. When I listened to my colleagues who were working on the frontiers of molecular neurobiology and argued for the usefulness of their work to our field and our College, I had to agree that they were correct. And when an observer heard me agree with both diametrically opposed positions, I had to agree with her view as well, which held that molecular neurobiology has a real contribution to make to our field-on a selective basis.

As my presidential year began, I was on sabbatical at Stanford where I had the opportunity to reflect on 25 years of research in the addictions field. I learned some molecular biology from texts and came to the conclusion that the addictions field was ready for the paradigm shift. Perhaps that explains my career change to full-time administration.

On the other hand, I was dismayed to realize that too many molecular neurobiologists were focused on acute experiments that merely sought to find intracellular concomitants of the reinforcing properties of drugs. Drug and alcohol dependence are chronic, relapsing disorders! I saw the next generation of clinical research reporting comorbidity according to DSM-IV, rather than exploring the rich theoretical possibilities of our roots in this field. In my judgment, DSM-IV needs to represent the "floor" and not the "ceiling" of our clinical data.

For all of the reasons presented in Table 1, of all of the areas of neuropsychopharmacology I believe that the addictions field is ready for the paradigm shift. Once we have begun to define the potential of the new science, we may be able to apply the paradigm to other areas of neuropsychopharmacology in a way that can highlight the interdependence of first class clinical investigation with first class molecular biology!

\section{REFERENCES}

Baldwin HA, Koob GF (1993): Rapid induction of conditioned opiate withdrawal in the rat. Neuropsychopharmacology 8(1):15-21

Bauer LO (1992): Neurophysiological Aspects of Cocaine vs Alcohol Withdrawal: Different Syndromes! - Different Treatments? Paper presented at the Annual Meeting of the American College of Neuropsychopharmacology, December 1992, San Juan, Puerto Rico

Beitner-Johnson D, Guitart X, Nestler EJ (1992): Common intracellular actions of chronic morphine and cocaine in dopaminergic brain reward regions. In The Neurobiology of Drug and Alcohol Addiction. New York, New York Annals, New York Academy of Sciences, Vol 654, pp 70-87

Britt MD, Wise RA (1983): Ventral tegmental site of opiate reward: Antagonism by a hydrophillic opiate receptor blocker. Brain Res 258:105-108

Bronstein DM, Prezewlocki R, Akil H (1990): Effects of morphine treatment on pro-opiomelanocortin systems in rat brain. Brain Res 519:102-111

Brown EE, Finlay JM, Wong JP, Damsma G, Fibiger HC, (1991): Behavioral and neurochemical interactions between cocaine and buprenorphine: Implications for the pharmacotherapy of cocaine abuse. J Pharmacol Exp Ther 256(1):119-126

Brown EE, Fibiger HC (1992): Cocaine-induced conditioned locomotion: absence of associated increases in dopamine release. J Neurosci 48(3):621-629

Buck KJ, Harris RA (1990a): Benzodiazepine agonist and inverse-agonist actions on GABAa receptor-operated chloride channels. I. Acute effects of ethanol. J Pharmacol Exp Ther 253:706-712

Buck KJ, Harris RA (1990b): Benzodiazepine agonist and inverse-agonist actions on GABAa receptor-operated chloride channels. II. Clinical effects of ethanol. J Pharmacol Exp Ther

Cador M, Dumas S, Cole BJ, et al. (1992): Behavioral sensitization induced by psychostimulants or stress: Search for a molecular basis and evidence for a CRF dependent phenomenon. In PW Kalivas and HH Samson (eds), The Neurobiology of Drug and Alcohol Addiction. New York, Annals New York Academy of Sciences, Vol 654, pp 416-420

Davis WM, Smith SG (1974): Naloxone use to eliminate opi- 
ate-seeking behavior: Need for extinction of conditioned reinforcements. Biol Psychiatry 9:181-189

DiChiara G, Imperato A (1988): Drugs Abused by Humans Preferentially Increase Synaptic Dopamine Concentrations in the Mesolimbic System of Freely Moving Rats. Proc Natl Acad Sci 85:5274-5278

Dole VP, Nyswander ME (1965): A Medical Treatment for Diacetylmorphine (Heroin) Addiction. JAMA 193(3):646-650

Finlay JM, Jakuvovic A, Phillips AG, Fibiger HC (1988): Fentanyl-induced conditional place preference: Lack of associated conditional neurochemical events. J Psychopharmacol 93:534-549

Fitzgerald LW, Nestler EJ: Molecular and cellular adaptations in signal transduction pathways following ethanol exposure. J Clin Neurosci (in press)

Gillin JC, Smith TL, Irwin M, et al. (1994): Increased pressure for rapid-eye movement sleep at time of hospital admission predicts relapse in nondepressed patients with primary alcoholism at 3-month follow-up. Arch Gen Psychiatry 51:189-197

Goeders NE, Lane JD, Smith JE (1984): Self-administration of methionine and enkephalin into the nucleus accumbens. J Pharmacol Biochem Behav 20:451-455

Grant KA, Valverius P, Hudspith M (1990): Ethanol withdrawal seizures in NMDA receptor complex. Eur J Pharmacol 176:289-296

Herning RI, Glover BJ, Guo X, et al. (1992): Excessive EEG east activity in cocaine abusers: Pharmacological Interventions. Paper delivered at the Annual Meeting of the American College of Neuropsychopharmacology, December 1992, San Juan, Puerto Rico

Higley JD, Hasert MF, Suomi SJ, Linnoila M (1991): Nonhuman primate model of alcohol abuse: Effects of early experience, personality, and stress on alcohol consumption. J Proc Natl Acad Sci 48A(88):7261-7265

Hodgson R, Rankin H, Stockwell T (1979): Alcohol dependence and the priming effect. J Behav Res Ther 17:379387

Kaplan RF, Meyer RE, Stroebel CF (1983): Alcohol dependence and responsivity to an ethanol stimulus as Predictors of alcohol consumption. B J Addictions 78:259-267

Karler R, Calder LD, Chauhry IA (1989): Blockade of "reverse tolerance" to cocaine and amphetamines by M.K. 801. Life Sci 45:599-606

Koob GF (1992a): Neural mechanisms of drug reinforcement. In PW Kalivas, HH Samson (eds), The Neurobiology of Drug and Alcohol Addiction. New York Academy of Sciences, 654:171-191

Koob GF (1992b): Neurobiologic mechanism in cocaine and opiate dependence. In CP O'Brien, JH Jaffe (eds), Addictive States. New York, Raven, pp 79-92

Koob, GF, Bloom FE (1988): Cellular and molecular mechanisms of drug dependence. Science 242:715-723

Kornetsky C, Porrino L (1992): Brain mechanisms of druginduced reinforcement. In CP O'Brien, JH Jaffe (eds), Addictive States. New York, Raven, pp 59-77

Kreek MJ (1992a): Rationale for maintenance pharmacotherapy of opiate dependence. In CP O'Brien, JH Jaffe (eds),
Addictive States. New York, Raven, 205-230

Kreed MJ (1992b): Neuroendocrinology of cocaine abuse. Paper delivered at the American College of Neuropsychopharmacology Annual Meeting, December 1992, San Juan, Puerto Rico

Kuhn T (1970): The Structure of Scientific Revolutions. Chicago, University of Chicago Press

Martin WR, Jasinski DR (1969): Physiologic parameters of morphine dependence in man-Tolerance, early abstinence and protracted abstinence. J Psych Res Vol 7(1):8-17

Meyer RE (1986): How to understand the relationship between psychopathology and addictive disorders: another example of the chicken and the egg. In RE Meyer (ed), Psychopathology and Addictive Disorders. New York, Guilford Press, pp 3-16

Meyer RE (1989): Prospects for a rational pharmacotherapy of alcoholism. J Clin Psy 50(11):403-412

Meyer RE, Dolinsky Z (1991): Alcohol reinforcement: biobehavioral and clinical considerations. In RE Meyer, JF Koob, MJ Lewis, SM Paul (eds), Neuropharmacology of Ethanol: New approaches. Birkhauser, Boston, pp 251264

Meyer RE, Mirin SM (1979): The Heroin Stimulus Implications for theory of Addiction. New York, Plenum

Morrow AL, Montpied P, Paul SL (1991): Ethanol and the GABA-A receptor-gated chloride ion channel. In $\mathrm{RE}$ Meyer, GF Koob, MJ Lewis, SM Paul, (eds), Neuropharmacology of Ethanol: New Approaches. Boston, Birkhauser, pp 49-76

Nestler, EJ (1990): Adaptive changes in signal transduction systems: Molecular mechanisms of opiate addiction in the rat locus coeruleus. Prog Cell Res 1:73-88

Nestler EJ (1994): Molecular neurobiology of drug addiction. J Neuropsychopharmacol 11(2):77-88

O'Brien CP, Childress AR, McLellan AT, et al. (1992): Classical conditioning in drug-dependent humans. In PR Kalivas, $\mathrm{HH}$ Samson (eds), The Neurobiology of Drug and Alcohol Addiction. New York, Annals of the New York Academy of Sciences, Vol 654, 400-415

$\mathrm{O}^{\prime}$ Brien CP, Testa, O'Brien TJ et al. (1977): Conditioned narcotic withdrawal in humans. Science 195:1000-1002

O'Malley SS, Jaffe AJ, Chang G, et al. (1992): Naltrexone and Coping Skills Therapy for Alcohol Dependence: A Controlled Study. Arch Gen Psychiatry 49:881-887

Pavlov IP (1926): Conditioned Reflexes. New York, Dover

Pettit HO, Ettenberg A, Bloom FE, et al. (1984): Destruction of dopamine in nucleus accumbens selectively attenuates cocaine but not heroin self-administration in Rats. J Psychopharmacol 84:167-173

Post RM, Wise SRB, Fontana D, et al. (1992): Conditioned sensitization to the psychomotor stimulant cocaine. In PW Kalivas, $\mathrm{HH}$ Samson (eds), The Neurobiology of Drug and Alcohol Addiction. New York, The New York Academy of Sciences, Vol 654, pp 386-399

Reed LD, Hunter GA (1984): Morphine and naloxone modulate intake of ethanol. Alcohol 1:33-37

Ritz MT, Lamb MC, Oldburg SR, Kuhar MJ (1987): Effects of cocaine on the dopamine transporter. Science 237:12191223 
Siegel S, Hinson RE, Krank MD (1987): Anticipation of pharmacologic and nonpharmacologic events: Classical conditioning and addictive behavior. J Drug Issues 17:83-110

Stewart J, DeWitt H, Eikelboom R (1984): Role of unconditioned and conditioned drug effects in the self-administration of opiates and stimulants. Psychol Rev 91:251-268

Stewart J, Vezina P (1988): Conditioning and behavioral sensitization. In PW Kalivas, C Barnes, (eds), Sensitization in the Nervous System. Press, New Jersey, Telford, pp 207-224

Vavrousek-Jakuba E, Cohen C, Shoemaker WJ (1990): Ethanol effects of CNS dopamine receptors: In vivo binding following voluntary ethanol intake in rats. In $C A$ Naranjo, EM Sellers (eds), Novel Pharmacological Intervention for Alcoholism. New York, Springer-Verlag, pp 372-374

Volkow MD, Fowler JS, Wolf AP, et al. (1991): Changes in brain glucose metabolism in cocaine dependence and withdrawal. Am J Psychiatry 148(5):621-626

Volkow MD, Hitzman R, Wang GJ, et al. (1992): Long-term frontal brain metabolic changes in cocaine abusers. Synapse 11(3):184-190

Volpicelli JR, Alterman AI, Hayashadi M, et al. (1992): Naltrexone in the treatment of alcohol dependence. Arch Gen Psychiatry 49:876-880

Weeks JR (1963): Experimental morphine addiction: The Methods for automatic intravenous injections in unrestrained rats. Science 138:143-144

Weiss F, Hurd YL, Ungerstedt U, et al. (1992): Neurochemical correlates of cocaine and ethanol self-administration. In PW Kalivas, HH Samson (eds), The Neurobiology of Drug and Alcohol Addiction. Annals of the New York Academy of Sciences 654:220-241

Wikler A (1948): Recent progress in research on the neurophysiologic basis of morphine addiction. Am J Psychiatry 105:329-338

Wikler A (1965): Conditioning factors in opiate addiction and relapse. In DM Wilmer and GG Kassebaum (eds), Narcotics. New York, McGraw-Hill, pp 85-100

Wikler A, Pescor FT (1967): Classical conditioning of morphine abstinence reinforcement of opioid-drinking behavior and relapse in morphine-addicted rats. J Psychopharmacologia 10:255-284

Wise RA, Bozarth MA (1987): A psychomotor stimulant theory of addiction. Psychol Rev 94(4):469-492

Woods JH, Schuster CR (1968): Reinforcement properties of morphine, cocaine, and SPA as a function of unit dose. Int J Addictions III:231-237

Yanagita T, Kiyoshi A, Takahashi S, et al. (1969): Self-Administration of Barbiturates, Alcohol (Intragastric), and CNS Stimulants (Intravenous) in Monkeys in NAS-NRC Committee on Problems of Drug Dependence. Palo Alto, CA pp 6039-6051

Yokel RA, Wise RA (1975): Increased lever pressing for amphetamine after pimozide in rats: Implications for a dopamine theory of reward. Science 187:547-549 